\title{
Evaluation of "One Body, One Life": A Community-Based Family Intervention for the Prevention of Obesity in Children
}

\author{
Marsha Towey, ${ }^{1}$ Ruth Harrell, ${ }^{2}$ and Berni Lee ${ }^{2}$ \\ ${ }^{1}$ Health and Physical Activity Team, Coventry City Council, 1st Floor West Orchard House, Coventry CV1 1GF, UK \\ ${ }^{2}$ Department of Public Health, NHS Coventry, Coventry CV1 2GQ, UK \\ Correspondence should be addressed to Marsha Towey, marsha.towey@coventry.gov.uk
}

Received 12 May 2011; Revised 15 July 2011; Accepted 21 July 2011

Academic Editor: Eric Doucet

Copyright ( 2011 Marsha Towey et al. This is an open access article distributed under the Creative Commons Attribution License, which permits unrestricted use, distribution, and reproduction in any medium, provided the original work is properly cited.

\begin{abstract}
Service evaluation of a community-based healthy lifestyle programme, designed for families aimed at preventing obesity. Physiological and behaviour measures were recorded at the beginning and end of the programme. Out of a total of 454 participants, 358 (79\%) completed. From these completers 293 (64\%) were analysed as there was sufficient data. The use of "high visibility recruitment" led to $77 \%$ of completers being from Coventry's two most deprived population quintiles. Ethnic minorities were also well represented. There were statistically significant self-reported behaviour changes, with improvements in fruit and vegetables eaten and decrease in consumption of crisps, snacks, and take away foods. There were also significant increases in physical activity. There were small but statistically significant improvements in BMI/BMI percentile for adults and children who started the programme overweight/obese. These results demonstrate the programmes' effectiveness in enabling behaviour change, and attracting participants from deprived communities.
\end{abstract}

\section{Introduction}

The prevalence of obesity in children and adults has increased dramatically, with $62 \%$ of adults and $30 \%$ of children in England being overweight or obese, [1]. Reducing this "Global epidemic" through the prevention and management of obesity is therefore a public health priority [2]. The consequences of obesity on physical and mental health have been well documented in both adults and children and include hypertension, type II diabetes, increased social isolation, and reduced body image, [3].

Two Cochrane systematic reviews, one looking at prevention of childhood obesity [4] and the second at treatment [5], found limited evidence of effectiveness of interventions on weight; the most effective interventions combined dietary, physical activity, and behavioural components along with parental involvement. This reflects a "lifestyle management" approach [6]. Although changes in diet and physical activity could enable short-term weight loss, a lifestyle approach mandates that these two activities are underpinned by behavioural change strategies which will help to sustain changes over time, that is, goal setting and/or involvement of parents [7].
Behavioural change strategies are generally based on behavioural theories such as social cognitive theory and make the assumption that all behaviour patterns are conditioned. Altering these patterns is the key to changing and maintaining behavioural changes. Successful interventions therefore include modeling to change behaviour with reinforcement (operant conditioning) $[8,9]$ to embed change. The involvement of the family, to ensure that the home environment is conducive to modeling and particularly reinforcement, is therefore important for change to occur and be sustained [10].

Having one or more obese parents is one of the best predictors of obesity in children [11]. Genetics aside, this demonstrates the influence of parents and the home environment in determining a child's diet and physical activity levels [12]. Direct involvement by at least one parent as an active partner in the weight loss process has been found to improve a child's short-term and long-term (1 year) weight regulation $[13,14]$. This is particularly so for children aged 6-11 years where parents are the primary mediator of change [13]. Research has repeatedly demonstrated the importance of parental involvement. A recent study by Watson et al. showed a strong positive association between adult BMI 
change and child BMI standard deviation scores (SDS) change, particularly after intervention when therapeutic contact was minimal [15]. It is important therefore that obesity interventions involve a parent in the process and hence a family-based programme is advocated. As Berry et al., identifies, the management of obesity in families is difficult due to the number of variables that need to be taken into account when designing an intervention, for example, age, environment, and culture [12].

The One Body, One Life (OBOL) programme has been designed with these principles in mind.

\section{Methods}

2.1. Development of One Body, One Life Programme. The OBOL programme is underpinned by a solutions-focused approach. This approach focuses on the client's perception of the problem rather than objective facts [16]. The theory emphasizes a client's strengths and focuses primarily on solutions rather than the problem [17]. It does not emphasise the past, except in relation to present and future solutions. Hoyt and Berg summarise the basic rules as (1) if it ain't broke, do not fix it; (2) once you know what works, do more of it; and (3) if something does not work, do not do it again; do something different [18]. The main focus is on simple adaptive solutions, as small changes can lead to more substantial changes.

The programme is also underpinned by "goal setting" theory [19] and self-monitoring theory [20] which have become the standard components of obesity interventions [12]. The aim of goal setting states that under certain conditions, setting specific challenging goals leads to higher performance when compared with no goals or vague, nonquantifiable goals such as "do your best", [19]. The aim of self-monitoring is to raise awareness of the individual's behavioural patterns so that they can assess changes over time [6].

The OBOL programme lasts for 10-12 weeks, with weekly 90-minute sessions. The sessions consist of a healthy eating and a physical activity workshop. Both workshops are held with adults and children together. The sessions are designed to be fun and interactive with key messages for everyone. The 45-minute healthy eating workshop provides participants with foundation knowledge in healthy eating to enable them to make healthier choices. Clients are encouraged to monitor their food intake, which is recognized as being more effective than food restriction, [21]. A 45minute physical activity workshop follows this. The main objective of this is the development of core motor skills, confidence, and self-esteem alongside improving fitness. Table 1 gives an overview of the sessions.

2.2. Recruitment. For the cohort included within this evaluation, the main recruitment strategy used was to raise awareness of the programme amongst the target population (the more deprived areas of Coventry) by making the programme and team members visible within the local community. This was done through health promotions, taster
TABLE 1: Overview of OBOL sessions.

\begin{tabular}{|c|c|}
\hline Healthy eating workshop & Physical activity workshop \\
\hline Health checks (Start and end) & Warm up \\
\hline $\begin{array}{l}\text { Healthy eating and physical } \\
\text { activity goal setting and review } \\
\text { using solutions focused techniques } \\
\text { (Week 2, } 6 \text { and 9) }\end{array}$ & $\begin{array}{l}\text { Skills development that is } \\
\text { strength, coordination, flex- } \\
\text { ibility, gentle fitness, con- } \\
\text { fidence, and sports specific } \\
\text { skills. }\end{array}$ \\
\hline Importance of water & $\begin{array}{l}\text { Fun activity integrating skills } \\
\text { learnt }\end{array}$ \\
\hline Importance of breakfast & Cool down \\
\hline Eat well plate 5 a day & Progression routes \\
\hline \multicolumn{2}{|l|}{ Food demonstration } \\
\hline \multicolumn{2}{|l|}{ Meal planning structured eating } \\
\hline \multicolumn{2}{|l|}{ Eating on a budget } \\
\hline \multicolumn{2}{|l|}{$\begin{array}{l}\text { Advertising hidden fats, salts, and } \\
\text { sugars }\end{array}$} \\
\hline \multicolumn{2}{|l|}{ Food labelling } \\
\hline \multicolumn{2}{|l|}{ Snacking } \\
\hline Progression routes & \\
\hline
\end{tabular}

sessions and briefings to neighbourhood groups in local venues (including schools), as well as through flyers, posters, the use of media, and a website.

The teams strategy was to target prospective clients in their "own environment" and focus on those most at risk. This meant that our primary target for health promotions/taster sessions was schools in deprived areas. Prior to an OBOL course being run, the team would liaise with headteachers, the healthy schools coordinator, and the school nurse to promote interest at the school. The main aim of the taster sessions was to give potential participants insight into what they could expect on the programme in a fun and interactive way. Assemblies and classroom sessions were used, where possible, involving parents. For older children the sessions were often integrated into school curriculum, that is, "destress session" on how healthy eating/physical activity can help with exam stress. Following the health promotion/taster session, the schools were asked to distribute letters to the parents giving them details of the future-planned local OBOL programme.

Local fete's and community groups were also used to promote uptake of the programme. Again taster sessions were provided or on occasion "health MOT's" were given to prospective clients. The team used this opportunity to promote the benefits of healthy eating and physical activity, whilst at the same time signposting them to programmes available within the local area.

The recruitment strategy also used newsletters and local newspapers to showcase successful case studies to highlight the benefits of the programme. Flyers, posters, and leaflets were also distributed in deprived areas in locations that were "highly visible" as well as in venues linked to the health agenda, for example, pharmacies, GP surgeries, libraries, children's centres, and schools. 
Of those recruited onto the programme, approximately $90 \%$ reported that they attended because of this recruitment strategy. The remainder were recruited through word of mouth, referrals from healthcare professionals or other (unknown) sources.

The OBOL programme recruits the whole family, where one or more member of the family is an "unhealthy weight" (underweight, overweight, or obese). This means that a participating child or adult may not be an unhealthy weight. The target age range for children is 7-16 years old, who must be accompanied by a parent although siblings outside this age range are included (especially where childcare facilities are an issue).

Baseline characteristics of the individuals were recorded at the first session. Physiological data and behaviour data was collected at the first and last sessions, using the same data collection instruments, as follows;

2.2.1. Physiological Measures. Weight was measured to the nearest $0.1 \mathrm{~kg}$; fat percentage, total body water (TBW), and visceral fat were measured using bioimpedance on the medically approved Tanita scales (BC420 MA). Height was measured to the nearest $1 \mathrm{~mm}$ with Leicester height measure; Child Growth Foundation, London. BMI (weight in $\mathrm{kg} /(\text { height in } \mathrm{m})^{2}$ ) was used for adults. For children this was converted into Z scores using UK 1990 data (Coles LMS). Waist circumference was measured to the nearest $0.1 \mathrm{~cm}$. Measurements were taken at the start and end of the programme.

2.2.2. Measurement of Knowledge and Behaviour. Healthy eating knowledge was estimated through a healthy eating quiz which looked at participants' knowledge of the Eat Well plate, vitamins, hidden fats and sugars, and so on. Participant's eating behaviours were recorded using a 24 hour recall questionnaire focusing on fruit and vegetable portions and fast food/unhealthy snacks intake.

Activity was measured through recall of previous week's activity. Clients self reported how many times they took part in activity for more than 30 minutes. During the programme, the measurement technique was altered from asking about activity in general to using specific activities (including household duties and walking up stairs) as prompts. Analysis here only included scores taken using prompts. Both measures were taken at the start and the end of the programme.

2.2.3. Ethics Approval. The analysis described in this paper was a formative evaluation for the purpose of improving the service offered. Clients gave permission for the data to be used for these purposes.

2.2.4. Statistical Analysis. The data analysed was routinely collected by the programme as part of the on-going monitoring arrangements and was used retrospectively for this evaluation. Data quality issues were dealt with by excluding results where there was a clear data entry error (missing or decimal point error). Where results were outliers of the distribution, the likelihood of the result being correct was considered, and if it was a physiological possible result, it was included within the analysis.

Statistical analysis was carried out using paired t-tests to compare the before and after measurements of individual participants, where both start and end data was provided. Subgroup analysis was carried out where relevant (e.g., $\mathrm{BMI} / \mathrm{BMI}$ percentile reduction was only an objective in those who were overweight or obese at entry to the programme). Outcome data at course completion was available for the cohort included in this evaluation; longer term outcomes are now being captured where possible.

\section{Results}

The programme was attended by 272 children and 182 adults (parent/carer) via 30 different courses, run in different locations and times (January 2008 to May 2009), but following the same format. Of these, 221 children $(81 \%)$ and $137(75 \%)$ adults completed the programme. Physiological data was recorded at the start and end of the intervention for 186 children and 107 adults, and the evaluation results are obtained from this group. Rates for completion were similar by ethnic group. The reasons given for dropping out of the course were varied (including parent starting new employment and difficulties within families). The average age of the children was 8 years, but the range was as wide as 0 to 15 years since; although the target range was $7-16$ yrs, siblings were encouraged to participate.

Table 2 shows the characteristics of the participants who completed and those who failed to complete the programme. It demonstrates that the weight profile of children attending the program is broadly similar to that measured in Year 6 through the NCMP programme in Coventry and to the Health Survey for England data for 2-15 year olds [22]. For adults, there are a higher proportion of obese participants (38\%) than reflected in the current Coventry population estimate of $25.6 \%$ [1]. The programme attracted an ethnically diverse group, with a lower proportion of those of white British ethnicity than estimated from the 2001 census [23]. The programme also attracted families from the more deprived areas in Coventry, with 252 (77\%) of the 326 attendees for whom postcode was available, coming from the two most deprived quintiles.

A comparison of the characteristics of those who failed to complete the programme with those who completed it shows that boys were less likely to drop out than girls, and that those of mixed ethnicity were more likely to drop out (though this is based on small sample size). There was no significant difference by BMI category, deprivation, or healthy lifestyle behaviours.

Overall, the vast majority of participants (86\%) were made aware of the programme through their child's school (which may include the school nurse), and a further $8 \%$ had heard through advertising or word of mouth. Very few $(<5 \%)$ were recommended via their family doctor. 
TABLE 2: Baseline data for OBOL participants, comparing those who completed the course with those who did not complete.

\begin{tabular}{|c|c|c|c|c|c|c|c|c|c|c|}
\hline & \multicolumn{4}{|c|}{ Completed course } & \multicolumn{4}{|c|}{ Did not complete course } & \multicolumn{2}{|c|}{$P$ value* } \\
\hline & Adults & & Children & & Adults & & Children & & Adults & Children \\
\hline \multicolumn{11}{|c|}{ Gender } \\
\hline Male & 18 & $13 \%$ & 111 & $50 \%$ & 7 & $16 \%$ & 16 & $31 \%$ & 0.68 & 0.017 \\
\hline Female & 119 & $87 \%$ & 110 & $50 \%$ & 38 & $84 \%$ & 35 & $69 \%$ & 0.875 & 0.155 \\
\hline Not known & 0 & & $<5$ & & 0 & & 0 & & & \\
\hline \multicolumn{11}{|c|}{ Ethnicity } \\
\hline Asian & 22 & $18 \%$ & 39 & $21 \%$ & $<5$ & $10 \%$ & 5 & $11 \%$ & 0.216 & 0.102 \\
\hline Black & 7 & $6 \%$ & 10 & $5 \%$ & $<5$ & $7 \%$ & $<5$ & $9 \%$ & 0.733 & 0.457 \\
\hline Mixed & $<5$ & $2 \%$ & $<5$ & $2 \%$ & $<5$ & $5 \%$ & 6 & $13 \%$ & 0.369 & 0.013 \\
\hline White & 93 & $75 \%$ & 129 & $71 \%$ & 33 & $79 \%$ & 32 & $68 \%$ & 0.641 & 0.709 \\
\hline Not given & 11 & & 38 & & $<5$ & & $<5$ & & & \\
\hline Other & $<5$ & & $<5$ & & 0 & & 0 & & & \\
\hline \multicolumn{11}{|c|}{ BMI } \\
\hline Obese & 53 & $39 \%$ & 40 & $19 \%$ & 16 & $36 \%$ & 6 & $10 \%$ & 0.72 & 0.133 \\
\hline Overweight & 36 & $26 \%$ & 30 & $14 \%$ & 13 & $29 \%$ & 6 & $10 \%$ & 0.743 & 0.410 \\
\hline Healthy weight & 45 & $33 \%$ & 130 & $63 \%$ & 15 & $33 \%$ & 47 & $77 \%$ & 0.954 & 0.067 \\
\hline Underweight & $<5$ & $2 \%$ & 7 & $3 \%$ & $<5$ & $2 \%$ & $<5$ & $3 \%$ & 0.991 & 0.973 \\
\hline Not known & & & $<5$ & & 0 & & $<5$ & & & \\
\hline \multicolumn{11}{|c|}{ Deprivation quintile } \\
\hline 1-Most deprived & 47 & $52 \%$ & 73 & $47 \%$ & 16 & $41 \%$ & 19 & $44 \%$ & 0.271 & 0.709 \\
\hline 2 & 23 & $25 \%$ & 47 & $31 \%$ & 12 & $31 \%$ & 15 & $35 \%$ & 0.522 & 0.588 \\
\hline 3 & 19 & $21 \%$ & 32 & $21 \%$ & 9 & $23 \%$ & 6 & $14 \%$ & 0.782 & 0.324 \\
\hline 4 & $<5$ & $1 \%$ & 0 & $0 \%$ & $<5$ & $3 \%$ & $<5$ & $2 \%$ & & \\
\hline 5-Least deprived & $<5$ & $1 \%$ & $<5$ & $1 \%$ & $<5$ & $3 \%$ & $<5$ & $5 \%$ & & \\
\hline \multirow[t]{2}{*}{ Not provided } & 46 & & 68 & & 6 & & 8 & & & \\
\hline & Mean & SD & Mean & $\mathrm{SD}$ & Mean & SD & Mean & SD & & \\
\hline Healthy living quiz & 68.2 & 18.7 & 66.3 & 20.5 & 71.0 & 12.4 & 66.5 & 22.9 & 0.274 & 0.944 \\
\hline Weekly activity & 10.5 & 6.0 & 9.9 & 6.3 & 10.0 & 7.6 & 10.8 & 8.1 & 0.691 & 0.431 \\
\hline Fruit and vegetable consumption & 2.9 & 1.5 & 2.9 & 1.6 & 3.1 & 1.5 & 2.9 & 1.5 & 0.312 & 0.99 \\
\hline Crisps, chips, and sweets & 1.5 & 1.2 & 1.8 & 1.3 & 1.5 & 1.2 & 1.9 & 1.2 & 0.978 & 0.858 \\
\hline Fast food & 1.2 & 1.0 & 1.4 & 1.2 & 1.3 & 1.3 & 1.6 & 1.3 & 0.53 & 0.613 \\
\hline
\end{tabular}

$P$ value is test difference between completed and dropped out.

SD: Standard deviation.

3.1. Behaviour Change. Table 3 shows the results for all measures of behaviour that were recorded for OBOL participants. There was a statistically significant improvement in knowledge of healthy eating and physical exercise both in adults and children, with an increased score of 11.5 points (out of 100) for children and 13.9 for adults (95\% confidence intervals 8.6-14.5 and 10.9-16.9, resp.).

Both adults and children achieved a statistically significant increase in their weekly activity levels, of over $3 \times 30$ minutes (for adults) and $3 \times 60$ minutes (for children) per week. It is possible that this change is in part due to the activity element of the programme, however this would be a maximum of 45 minutes, considerably less than the increase seen.

The number of participants consuming 5 or more portions of fruit and vegetables a day increased from $21 \%$ to $33 \%$, with an increase of 0.57 portions ( $95 \%$ confidence interval of $0.31-0.83, P<0.001$ ) per day for children and 0.76 portions ( $95 \%$ confidence interval of $0.47-1.06$, $P<0.001)$ per day for adults. There was also a significant reduction in the amount of chips, crisps, sweets, and fizzy drinks consumed per day. The reduction was of 0.32 portions per day (95\% confidence interval of 0.11 to $0.52, P=0.002$ ) for children and 0.34 portions per day (95\% confidence interval of 0.07 to $0.61, P=0.01$ ) for their parents.

Fast food consumption also decreased, but this was not statistically significant for children with a reduction of 0.21 portions per week, ( $95 \%$ confidence interval of -0.45 to $+0.03, P=0.08)$, but was for their parents with a reduction of 0.34 portions per week ( $95 \%$ confidence interval of 0.16 to $0.51, P<0.001)$.

3.2. Physiological. Table 4 shows the physiological outcomes, comparing baseline measures with those recorded at course end. This analysis was carried out for overweight 
TABLE 3: Summary of behaviour change among the 293 OBOL participants (107 adults and 186 children) for whom baseline and outcome data was available.

\begin{tabular}{|c|c|c|c|c|c|}
\hline & Change (average) & $95 \%$ & e interval & $P$ & Average at end of programme \\
\hline \multicolumn{6}{|c|}{ Knowledge } \\
\hline Children $(n=155)$ & 11.5 & 8.6 & 14.5 & $<0.001$ & 79.3 \\
\hline Adults $(n=91)$ & 13.9 & 10.9 & 16.9 & $<0.001$ & 81.6 \\
\hline \multicolumn{6}{|c|}{ Activity (adults units of 30 minutes, children units of 60 minutes per week) } \\
\hline Children $(n=162)$ & 3.9 & 2.5 & 5.2 & $<0.001$ & 13.9 \\
\hline Adult $(n=89)$ & 3.7 & 2.2 & 5.2 & $<0.001$ & 13.9 \\
\hline \multicolumn{6}{|c|}{ Fruit and vegetable portions per day } \\
\hline Children $(n=172)$ & 0.57 & 0.31 & 0.83 & $<0.001$ & 3.58 \\
\hline Adult $(n=97)$ & 0.76 & 0.47 & 1.06 & $<0.001$ & 3.63 \\
\hline \multicolumn{6}{|c|}{ Crisps, chips, sweets and, carbonated drinks per day } \\
\hline Children $(n=169)$ & -0.32 & -0.11 & -0.52 & 0.002 & 1.64 \\
\hline Adult $(n=97)$ & -0.34 & -0.07 & -0.61 & 0.013 & 0.91 \\
\hline \multicolumn{6}{|c|}{ Fast food per week } \\
\hline Children $(n=137)$ & -0.21 & -0.45 & 0.026 & 0.08 & 1.21 \\
\hline Adult $(n=99)$ & -0.34 & -0.16 & -0.51 & $<0.001$ & 0.84 \\
\hline
\end{tabular}

TABLE 4: Physiological changes, comparing baseline with course end measures for overweight or obese participants.

\begin{tabular}{|c|c|c|c|c|c|}
\hline & $n$ & mean change (\%) & 95\% confidence interval & Standard deviation & $P$ \\
\hline \multicolumn{6}{|c|}{ Adults obese and overweight } \\
\hline Body fat $\%$ & 66 & $-1.75 \%$ & $(-3.08--0.41)$ & $5.53 \%$ & 0.010 \\
\hline BMI & 67 & $-0.78 \%$ & $(-1.41--0.14)$ & $2.65 \%$ & 0.016 \\
\hline Waist circumference & 67 & $-1.95 \%$ & $(-2.82--1.06)$ & $3.68 \%$ & $<0.001$ \\
\hline Hip circumference & 63 & $-1.32 \%$ & $(-1.99--0.64)$ & $2.73 \%$ & $<0.001$ \\
\hline Heart rate & 67 & $-1.94 \%$ & $(-4.97-1.1)$ & $12.70 \%$ & 0.212 \\
\hline Systolic blood pressure & 65 & $-3.68 \%$ & $(-6.83--0.53)$ & $12.96 \%$ & 0.022 \\
\hline Diastolic blood pressure & 65 & $-2.34 \%$ & $(-5.51-0.84)$ & $13.10 \%$ & 0.151 \\
\hline Expiratory volume & 68 & $7.56 \%$ & $(3.31-11.8)$ & $17.85 \%$ & $<0.001$ \\
\hline Visceral fat & 48 & $-0.68 \%$ & $(-4.7-3.34)$ & $14.23 \%$ & 0.741 \\
\hline TWB\% & 48 & $1.26 \%$ & $(0.53-1.98)$ & $2.57 \%$ & 0.001 \\
\hline \multicolumn{6}{|c|}{ Children obese and overweight } \\
\hline Body fat $\%$ & 57 & $-3.20 \%$ & $(-6.15--0.25)$ & $11.36 \%$ & 0.033 \\
\hline BMI percentile & 54 & $-1.82 \%$ & $(-3.14--0.5)$ & $4.95 \%$ & 0.007 \\
\hline Waist circumference & 57 & $-1.56 \%$ & $(-2.54--0.58)$ & $3.77 \%$ & 0.002 \\
\hline Heart rate & 50 & $-6.24 \%$ & $(-11.56--0.91)$ & $19.22 \%$ & 0.022 \\
\hline Systolic blood pressure & 48 & $2.94 \%$ & $(-2.81-8.69)$ & $20.35 \%$ & 0.317 \\
\hline Diastolic blood pressure & 48 & $6.11 \%$ & $(-2.84-15.06)$ & $31.65 \%$ & 0.181 \\
\hline Expiratory volume & 58 & $9.13 \%$ & $(5.35-12.9)$ & $14.67 \%$ & $<0.001$ \\
\hline
\end{tabular}

and obese participants only, since this group might be expected to see changes due to their behaviour change. For overweight and obese parents and children, a number of measures including BMI (BMI percentile for children), body fat $\%$ and waist circumference showed a statistically significant difference at the end of the course compared to the initial measurement. Each of the statistically significant changes reflected an improvement; however, the scale of improvements was small and is unlikely to be clinically significant. Although these changes are not expected to impact on the short-term health of the individuals, if this reported behaviour change is sustained, future health improvements should be anticipated.

Intention to treat analysis, which assumes no change for those who dropped out of the course, was also carried out; compared to the data shown, the same measures were found to be statistically significant, but with a smaller size effect.

\section{Discussion}

A change in knowledge of healthy lifestyles and behaviour in terms of physical activity and healthy eating has been 
demonstrated during the course of the programme. If these changes in behaviour are sustained, this might be expected to lead to a reduction in health risk factors for adults [2426]. In addition, since parents are the primary mediators of change, [13] parental eating and physical activity choices will inevitably impact on the home environment, making it more conducive to positive change in children [15]. Research supports this assumption by demonstrating that weight control interventions delivered within a family-based context have yielded very promising long-term results in the treatment of childhood obesity [27]. This 10-year followup study demonstrated that $34 \%$ of obese children maintained a decrease in BMI percentile, and 30\% were no longer overweight. This was only the case where at least one parent was involved in the intervention; if neither parent had been involved the benefits only lasted 5 years.

Overweight and obese adults and children have also shown small but statistically significant changes in physiological parameters (BMI/BMI percentile, waist circumference, and body fat) in the short term. This highlights the possibility of utilizing the programme to both prevent and treat childhood obesity, since family-based lifestyle interventions with a behavioural program aimed at changing diet and physical activity together with thinking patterns have been shown to be effective at treating childhood obesity, [5].

The effectiveness of the recruitment strategy in reaching higher deprivation groups, with a cross section of ethnicity, suggests that taking a "high visibility" approach in the local community is effective, even though it is labour and time intensive. Importantly in the context of the prevention of childhood obesity, the proportion of obese adults (33\%) was higher than estimates of the local population $(26 \%)$. The recruitment strategy was inclusive and reached the target audience, as demonstrated through observation of the demographic profile of course participants shown in Table 2. This was achieved through promotion of OBOL in the target communities rather than through applying exclusions. This type of "inclusive" approach to recruitment supports Marmot's philosophy on tackling health inequalities; interventions that are "universal but targeted at those most at need" [28].

Another indirect benefit could also be that "inclusivity" reduces negative attitudes towards overweight/obese people. As Faith et al. suggests obese and nonobese individuals working together on a common problem might be an effective means for reducing antiobese attitudes [29]. It could be argued that "One Body, One Life" has a common goal of helping clients to lead a healthier life. Clients often share experiences and work together to come up with strategies of how they can do this in their everyday life. A byproduct of the programme could be that non overweight/obese clients improve their attitudes toward overweight and obese people. At a societal level this could have numerous benefits [29].

\section{Limitations of Research}

Clearly this is an evaluation of a service and not a research programme, and there are limitations to the study. For example, there is no control group, and so spontaneous changes in behaviour of the whole population cannot be ruled out. Given the study design, a further limitation is that the findings only relate to short-term impact, during the 1012 weeks of the programme, and it is not known whether changes are sustained. Efforts are underway to improve this; as with other like services, collection of longer term outcome data is problematic [30].

It should also be noted that the results were self-reported, and that participants may have overstated improvements in their healthy eating and physical activity. This could have been influenced by the demand characteristics of the setting and is known as the "teaching test" where clients report what they think the programme leader wants to hear [31].

Moreover, the data collection tools that were used for the courses described in this evaluation were developed specifically for this programme. However, to provide consistency, minimize the "teaching test" and allow better comparison with other programmes, validated questionnaires are recommended. Since this evaluation the programme has started to use such questionnaires.

\section{Future Research}

Research into the prevention and treatment of obesity is still emerging, and there are still many areas that are not fully understood. One area of interest that is highlighted within this research is the longer term impact of interventions. In relation to the following areas are changes maintained over a period of time. Do children or adults benefit most from interventions over time? Is it changes in eating habits, or changes in physical activity levels that are most effective at helping a client to maintain a healthy weight? Finally, more research is needed into understanding what type of programme best suits particular types of clients that is a treatment only programme needed just for obese clients, or in some circumstances can a more inclusive approach be more beneficial?

\section{Conflicts of Interest}

There are no conflicts of interest. It should be noted that Marsha Towey is the manager of the team who deliver the "One Body One life" programme. The PCT commissioned the programme as part of Coventry's Healthy Weight Strategy, the commissioning team was led by Berni Lee. Ruth Harrell was part of this commissioning team.

\section{Acknowledgments}

The authors would like to thank the One Body One Life team, without their hard work, enthusiasm, and passion these results would not have been possible. This programme was funded by the following organizations: Coventry City Council, NHS Coventry, and the Football Foundation. 


\section{References}

[1] R. Craig, J. Mindell, and V. Hirani, Health Survey for England 2008: Physical Activity and Fitness, vol. 1, Health and Social Care Information Centre, 2009.

[2] Department of Health, Healthy Weight Healthy Lives: A Cross Government Strategy for England, Crown, England, UK, 2008.

[3] B. Kolody and J. F. Sallis, "A prospective study of ponderosity, body image, self-concept, and psychological variables in children," Journal of Developmental and Behavioral Pediatrics, vol. 16, no. 1, pp. 1-5, 1995.

[4] C. D. Summerbell, E. Waters, L. D. Edmunds, S. Kelly, T. Brown, and K. J. Campbell, "Interventions for preventing obesity in children," Cochrane Database of Systematic Reviews, no. 3, Article ID CD001871, 2005.

[5] H. Oude Luttikhuis, L. Baur, H. Jansen et al., "Interventions for treating obesity in children," Cochrane Database of Systematic Reviews, no. 1, Article ID CD001871, pp. 1-185, 2009.

[6] C. Tyler, C. A. Johnston, and J. P. Foreyt, "Themed review: lifestyle mangement of obesity," American Journal of Lifestyle Medicine, vol. 1, pp. 423-429, 2007.

[7] G. S. Goldfield, H. A. Raynor, and L. H. Epstien, "Treatment of pediatric obesity," in Handbook of Obesity Treatment, T. A. Waddent and A. J. Stunkard, Eds., vol. 1, pp. 532-555, Guildford, New York, NY, USA, 2002.

[8] A. Bandura, Social Learning Theory, Prentice Hall, Englewood Cliffs, NJ, USA, 1977.

[9] A. Bandura, Self-Efficacy: The Exercise of Control, Freeman, New York, NY, USA, 1997.

[10] S. T. St Jeor, R. L. Brunner, M. E. Harrington et al., "A classification system to evaluate weight maintainers, gainers, and losers," Journal of the American Dietetic Association, vol. 97, no. 5, pp. 481-488, 1997.

[11] K. D. Brownell and J. P. Foreyt, Eds., Handbook of Eating Dis-Orders: Physiology, Psychology, and Treatment of Obesity, Anorexia and Bulimia, Basic, New York, NY, USA, 1986.

[12] D. Berry, R. Sheehan, R. Heschel, K. Knafl, G. Melkus, and M. Grey, "Family-based interventions for childhood obesity: a review," Journal of Family Nursing, vol. 10, no. 4, pp. 429-449, 2004.

[13] L. H. Epstein, "Family-based behavioural intervention for obese children," International Journal of Obesity, vol. 20, no. 1, pp. S14-S21, 1996.

[14] T. A. Wadden and A. J. Stunkard, Handbook of Obesity Treatment, Guildford, New York, NY, USA, 2002.

[15] P. M. Watson, D. Lindsey, P. Katie et al., "A whole family approach to childhood obesity management (GOALS): relationship between adult and child BMI change," Annals of Human Biology, vol. 38, no. 4, pp. 445-452, 2011.

[16] C. E. Murray and T. L. Murray, "Solution-focused premarital counseling: helping couples build a vision for their marriage," Journal of Marital and Family Therapy, vol. 30, no. 3, pp. 349358, 2004.

[17] B. O'Connell, Solutions Focused Therapy, Sage, London, UK, 1998.

[18] M. F. Hoyt and I. K. Berg, "Solutions-focused couple therapy: helping clients construct self-fulling realities," in Case Studies in Couple and Family Therapy: Systemic and Cognitive Perspectives, F. M. Dattilio, Ed., pp. 203-232, Guildford Press, New York, NY, USA, 1998.

[19] V. J. Strecher, G. H. Seijts, G. J. Kok et al., "Goal setting as a strategy for health behavior change," Health Education Quarterly, vol. 22, no. 2, pp. 190-200, 1995.
[20] L. A. Berkel, W. S. C. Poston, R. S. Reeves, and J. P. Foreyt, "Behavioral interventions for obesity," Journal of the American Dietetic Association, vol. 105, supplement 1, pp. S35-S43, 2005.

[21] W. Robertson, T. Friede, J. Blissett, M. C. J. Rudolf, M. Wallis, and S. Stewart-Brown, "Pilot of "families for health": community-based family intervention for obesity," Archives of Disease in Childhood, vol. 93, no. 11, pp. 921-928, 2008.

[22] Health Survey for England 2003-05 synthetic estimates at PCO level, NHS Information Centre, http://www.ic.nhs.uk/webfiles/Popgeog/Model Based Estimates of Obesity \%28adults\% 29 for PCOs in England\%2C 2003-2005.xls.

[23] Office for National Statistics (NOMIS), Census 2001 S101 Sex and Age by ethnic group.

[24] J. P. Foreyt and W. S. C. Poston III, "Enhancing weight loss and maintenance: augmenting drug treatment with exercise," 1996.

[25] G. L. Blackburn, "Effects of weight loss on weight-related risk factors," in Eating Disorders and Obesity: A Comprehensive Handbook, K. D. Brownell and C. G. Fairburn, Eds., pp. 406410, Guildford, New York, NY, USA, 1995.

[26] D. J. Goldstein, "Beneficial health effects of modest weight loss," International Journal of Obesity, vol. 16, no. 6, pp. 397415, 1992.

[27] L. H. Epstein, A. M. Valoski, M. A. Kalarchian, and J. McCurley, "Do children lose and maintain weight easier than adults: a comparison of child and parent weight changes from six months to ten years," Obesity Research, vol. 3, no. 5, pp. 411-484, 1995.

[28] M. Marmot, J. Allen, P. Goldblatt et al., "The Marmot Review: fair society fair lives: a strategic review of health inequalities in England Post 2010," 2010, http://www.ucl.ac .uk/gheg/marmotreview/.

[29] M. S. Faith, K. R. Fontaine, L. J. Cheskin, and D. B. Allison, "Behavioral approaches to the problems of obesity," Behavior Modification, vol. 24, no. 4, pp. 459-493, 2000.

[30] D. Upton, P. Upton, J. Bold, and D. M. Peters, Regional Evaluation of Weight Management Programmes for Children and Families, Report Commissioned by the Department of Health West Midlands, 2010.

[31] A. Kazdin, Research Design in Clinical Psychology, Allyn \& Bacon, Boston, Mass, USA, 1992. 


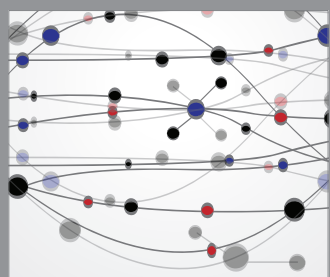

The Scientific World Journal
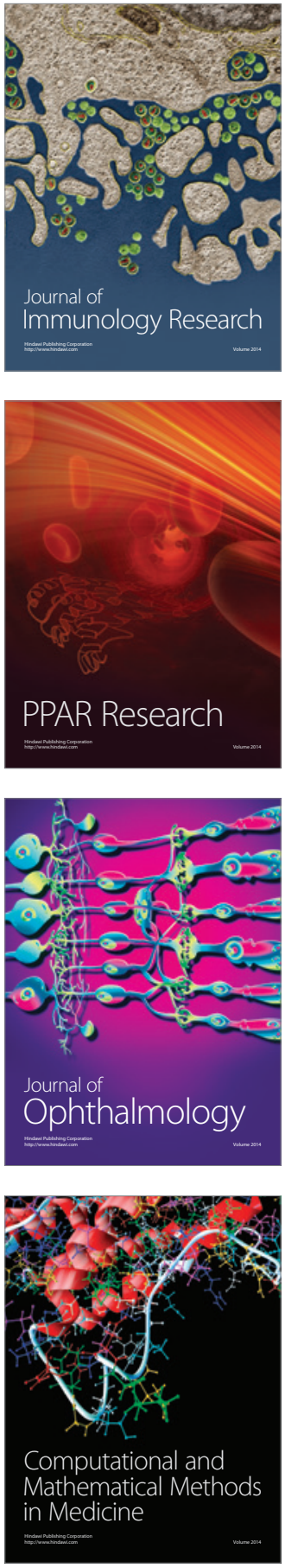

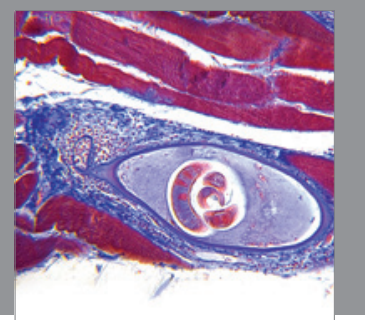

Gastroenterology

Research and Practice
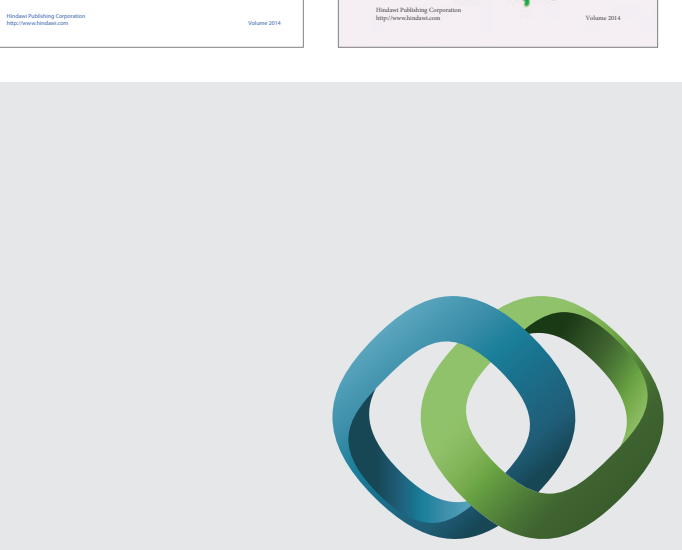

\section{Hindawi}

Submit your manuscripts at

http://www.hindawi.com
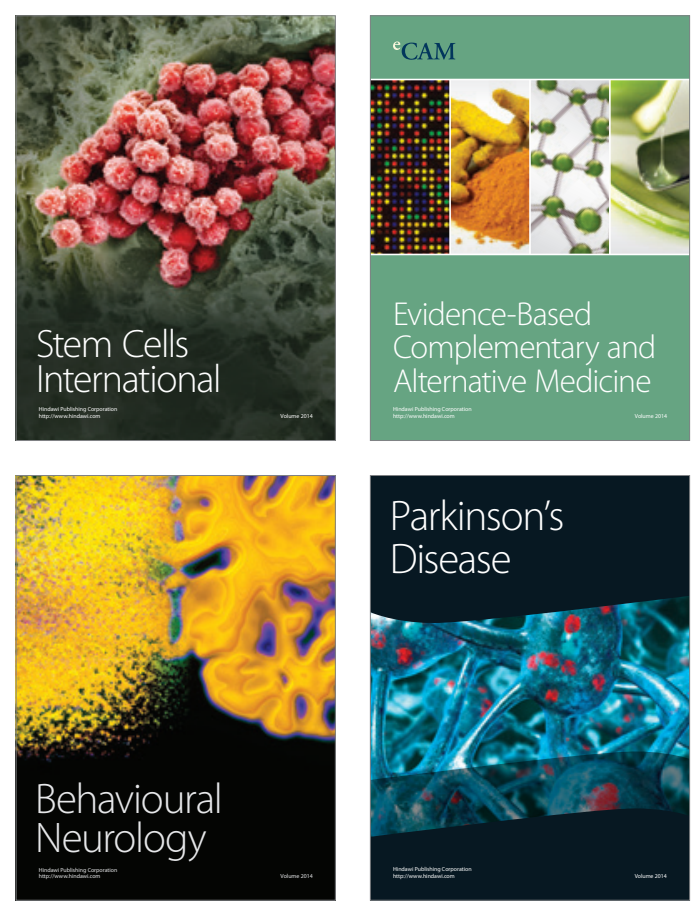

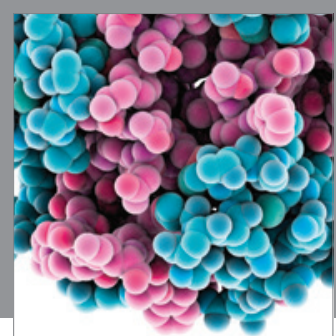

Journal of
Diabetes Research

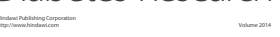

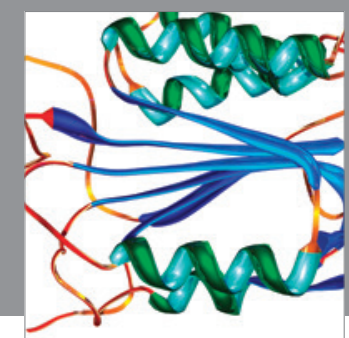

Disease Markers
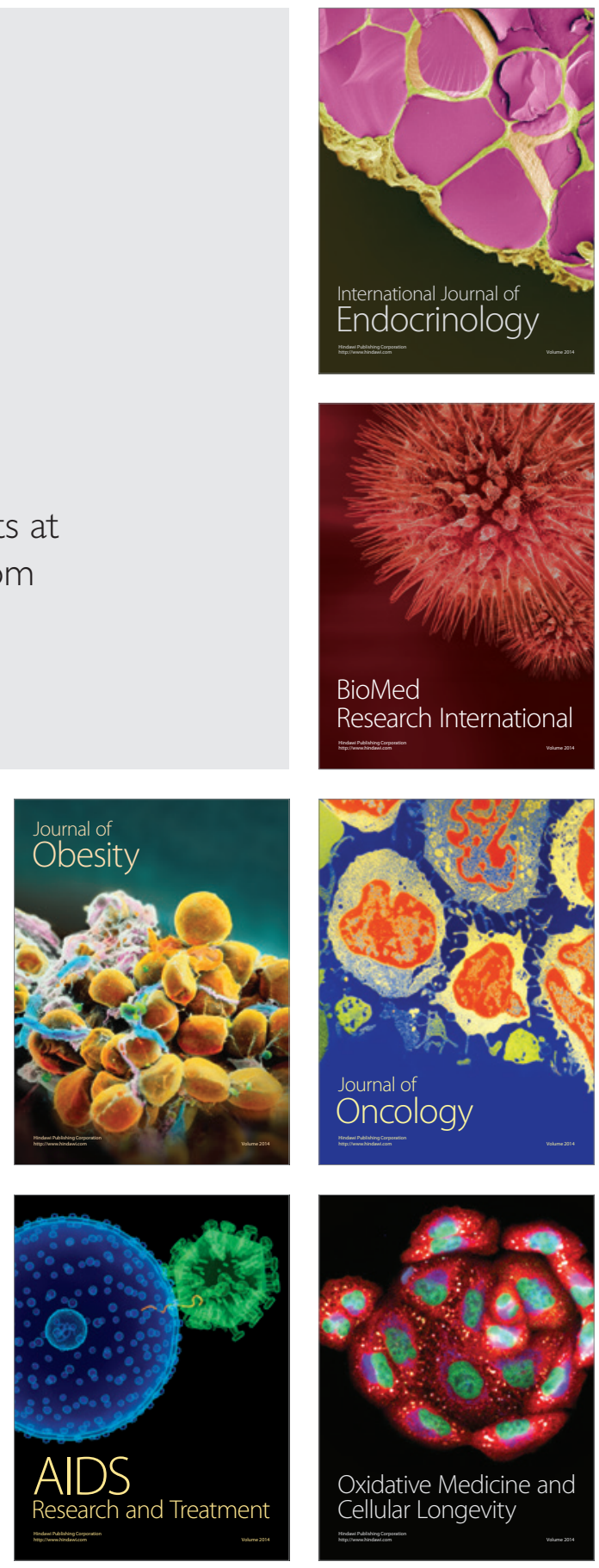